\begin{tabular}{|c|c|}
\hline Title & Equivalent networks for SA W gratings \\
\hline Author(s) & Koshiba, M.; Mitobe, S. \\
\hline Citation & $\begin{array}{l}\text { IEEE Transactions on U/trasonics, Ferroelectrics and Frequency Control, 35(5), 531-535 } \\
\text { https://doi.org/10.1109/58.8030 }\end{array}$ \\
\hline Issue Date & 198809 \\
\hline Doc URL & http:/hdl .handle.net/2115/6073 \\
\hline Rights & $\begin{array}{l}\text { () } 1988 \text { IEEE. Personal use of this material is permitted. However, permission to reprint/republish this material for } \\
\text { advertising or promotional purposes or for creating new collective works for resale or redistribution to servers or lists, } \\
\text { or to reuse any copyrighted component of this work in other works must be obtained from the IEEE." } \\
\text { IEEE, IEEE Transactions on Ultrasonics, Ferroelectrics and Frequency Control, } \\
\text { V olume } 35, \text { I Issue } 5,1988 \text { Page(s): } 531 \text { - } 535\end{array}$ \\
\hline Tyре & article \\
\hline File Information & ITUFFC35-5.pdf \\
\hline
\end{tabular}

Instructions for use 


\title{
Equivalent Networks for SAW Gratings
}

\author{
MASANORI KOSHIBA, SENIOR MEMBER, IEEE, AND SEIICHI MITOBE
}

\begin{abstract}
An equivalent network approach is described for the analysis of surface acoustic wave gratings. Circuit parameters can be theoretically determined by applying the finite-element method to an infinite array. In this approach, all of the effects of piezoelectric perturbation, mechanical perturbation, and energy storage are taken into account. To show the validity and usefulness of this approach, examples are computed for groove and metallic gratings. Both short and open circuited metallic gratings are treated. For grooves on isotropic and $Y-Z \mathrm{LiNbO}_{3}$ substrates, the dependence of reflection characteristics on groove depth is investigated. For aluminum strips on $X$ $112^{\circ} \mathrm{YLiTaO}_{3}, 34^{\circ} Y-X$ quartz, $Y-Z \mathrm{LiNbO}_{3}$, and $128^{\circ} Y-X \mathrm{LiNbO}_{3}$ substrates, the dependence on metallization ratio is investigated in detail.
\end{abstract}

\section{INTRODUCTION}

A N EQUIVALENT CIRCUIT of a step discontinuity in surface-acoustic-wave (SAW) gratings is of interest in many SAW devices such as delay lines, filters, reflectors, and resonators for signal processing applications. The equivalent network approach does have the very definite virtues of minimizing the algebra required in the analysis and furnishing physical insight, and has been applied to various SAW gratings such as groove [1]-[3] and metallic gratings [4]-[16]. In this approach, however, it is difficult to consider all of the effects of piezoelectric perturbation, mechanical perturbation, and energy storage due to evanescent bulk waves. Also, in general, circuit parameters have been empirically determined.

In this paper, a theoretical method for determining circuit parameters for SAW gratings is described. The finiteelement method (FEM) [17]-[19] is used to calculate the dispersion curves of an infinite array. Circuit parameters are then calculated by matching the dispersion curve from the equivalent network with that obtained by the FEM. In this approach, all of the effects of piezoelectric perturbation, mechanical perturbation, and energy storage are taken into account. To show the validity and usefulness of this approach, examples are computed for groove and metallic gratings. Both short and open circuited metallic gratings are treated. For grooves on isotropic and $Y-Z$ $\mathrm{LiNbO}_{3}$ substrates, the dependence of reflection characteristics on groove depth is investigated. For aluminum strips on $X-112^{\circ} Y \mathrm{LiTaO}_{3}, 34^{\circ} Y-X$ quartz, $Y$ - $Z \mathrm{LiNbO}_{3}$, and $128^{\circ} Y-X \mathrm{LiNbO}_{3}$ substrates, the dependence on metallization ratio is investigated in detail.

Manuscript received June 15, 1987.

The authors are with the Department of Electronic Engineering, Hokkaido University, Sapporo, 060 Japan.

IEEE Log Number 8821919.

\section{Equivalent Network Model}

We consider a groove or metallic grating with period $d$ on a surface of a piezoelectric crystal as shown in Fig. 1(a) and 2(a), respectively, where $d_{g}$ and $h$ in Fig. 1(a) are the width and depth of a groove, respectively, and $d_{m}$ and $h$ in Fig. 2(a) are the width and thickness of a metal strip, respectively. The groove or metallic grating can be modeled by the equivalent network [1] in Fig. 1(b) or 2(b), respectively, where $k_{f}$ and $k_{m}$ are the wavenumbers for Rayleigh waves on free and metallized surfaces, respectively, $Y_{0}$ and $Y_{0}^{\prime}$ are the characteristic admittances, and $B$ is the susceptance representing the energy storage effect. The wavenumbers $k_{f}$ and $k_{m}$ are calculated by the relations $k_{f}=2 \pi f / v_{f}$ and $k_{m}=2 \pi f / v_{m}$, respectively, where $f$ is the frequency, and $v_{f}$ and $v_{m}$ are the Rayleigh wave velocities on free and metallized surfaces, respectively.

\section{Determination of Circuit Parameters}

In the equivalent network in Figs. 1(b) or 2(b), a section of one period corresponding to the center distance between neighboring ungrooved or unmetallized parts is chosen as a unit circuit. The elements $A_{1}, B_{1}, C_{1}$, and $D_{1}$ of the standard transfer matrix for this unit circuit are calculated as

$$
A_{1}=c^{\prime} c-\frac{B}{Y_{0}} c^{\prime} s-\frac{B}{Y_{0}^{\prime}} s^{\prime} c+\frac{1}{2}\left(\frac{B}{Y_{0}} \frac{B}{Y_{0}^{\prime}}-\frac{Y_{0}^{\prime}}{Y_{0}}-\frac{Y_{0}}{Y_{0}^{\prime}}\right) s^{\prime} s
$$

$$
\begin{aligned}
B_{1}= & j \frac{1}{Y_{0}}\left[\frac{B}{Y_{0}} c^{\prime} c+c^{\prime} s-\frac{1}{2}\left(\frac{B}{Y_{0}} \frac{B}{Y_{0}^{\prime}}-\frac{Y_{0}^{\prime}}{Y_{0}}-\frac{Y_{0}}{Y_{0}^{\prime}}\right) s^{\prime} c\right. \\
& \left.-\frac{B}{Y_{0}^{\prime}} s^{\prime} s-\frac{B}{Y_{0}} c^{\prime}+\frac{1}{2}\left(\frac{B}{Y_{0}} \frac{B}{Y_{0}^{\prime}}-\frac{Y_{0}^{\prime}}{Y_{0}}+\frac{Y_{0}}{Y_{0}^{\prime}}\right) s^{\prime}\right]
\end{aligned}
$$

$$
\begin{aligned}
C_{1}= & j Y_{0}\left[\frac{B}{Y_{0}} c^{\prime} c+c^{\prime} s-\frac{1}{2}\left(\frac{B}{Y_{0}} \frac{B}{Y_{0}^{\prime}}-\frac{Y_{0}^{\prime}}{Y_{0}}-\frac{Y_{0}}{Y_{0}^{\prime}}\right) s^{\prime} c\right. \\
& \left.-\frac{B}{Y_{0}^{\prime}} s^{\prime} s+\frac{B}{Y_{0}} c^{\prime}-\frac{1}{2}\left(\frac{B}{Y_{0}} \frac{B}{Y_{0}^{\prime}}-\frac{Y_{0}^{\prime}}{Y_{0}}+\frac{Y_{0}}{Y_{0}^{\prime}}\right) s^{\prime}\right]
\end{aligned}
$$

$D_{1}=A_{1}$

where

$$
\begin{aligned}
& c=\cos \left(2 \pi f d_{d} / v_{f}\right) \\
& s=\sin \left(2 \pi f d_{f} / v_{f}\right)
\end{aligned}
$$




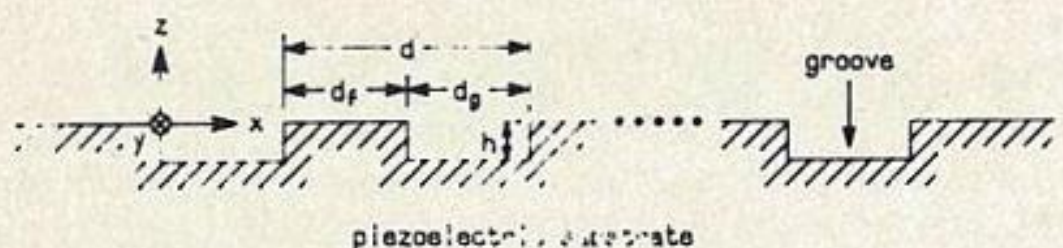

(a)

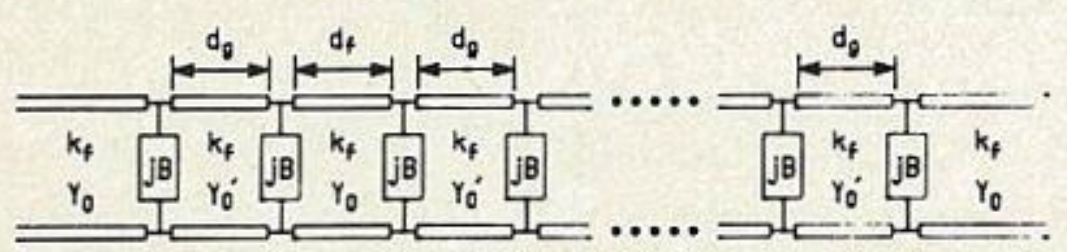

(b)

Fig. 1. Groove grating. (a) Configuration. (b) Equivalent network.
For an infinite array the dispersion relation is given by

$$
\cos \beta d=\left(A_{1}+D_{1}\right) / 2
$$

where $\beta$ is the phase constant in the $x$ direction.

Substituting (1) into (3), considering the first Bragg condition $\beta d=\pi$, and putting the lower and upper cutoff frequencies of the first stop band to $f_{l}$ and $f_{u}$, respectively, we obtain

$$
\begin{aligned}
1+ & c_{l}^{\prime} c_{l}-\hat{B} c_{l}^{\prime} s_{l}-\frac{\hat{B}}{1+\epsilon} s_{l}^{\prime} c_{l} \\
& +\left(\frac{1}{2} \frac{\hat{B}^{2}-\epsilon^{2}}{1+\epsilon}-1\right) s_{l}^{\prime} s_{l}=0 \\
1+ & c_{u}^{\prime} c_{u}-\hat{B} c_{u}^{\prime} s_{u}-\frac{\hat{B}}{1+\epsilon} s_{u}^{\prime} c_{u} \\
& +\left(\frac{1}{2} \frac{\hat{B}^{2}-\epsilon^{2}}{1+\epsilon}-1\right) s_{u}^{\prime} s_{u}=0
\end{aligned}
$$

where

$$
\begin{aligned}
& \epsilon=\left(Y_{0}^{\prime} / Y_{0}\right)-1 \\
& \hat{B}=B / Y_{0} .
\end{aligned}
$$

Here $c_{l}, s_{l}, c_{l}^{\prime}$, and $s_{l}^{\prime}$ are given by replacing $f$ in (2) by the lower cutoff frequency $f_{l}$, and similarly, $c_{u}, s_{u}, c_{u}^{\prime}$, and $s_{u}^{\prime}$ are given by replacing $f$ in (2) by the upper cutoff frequency $f_{u}$.

The cutoff frequencies $f_{l}$ and $f_{u}$ are easily calculated by applying the FEM to an infinite array [17]-[19]. Therefore, the values of the admittance mismatch $\epsilon$ and the normalized susceptance $\hat{B}$ are determined by solving (4) and (5) simultaneously. Since there are plural pairs of simultaneous solutions $(\epsilon, \hat{B})$ of $(4)$ and $(5)$, one should choose a pair of solutions appropriate to circuit parameters. The appropriate circuit parameters for SAW gratings should satisfy the following conditions:

$$
|\epsilon| \ll 1,|\hat{B}| \ll 1 \quad \text { for } h / \lambda_{f} \ll 1
$$

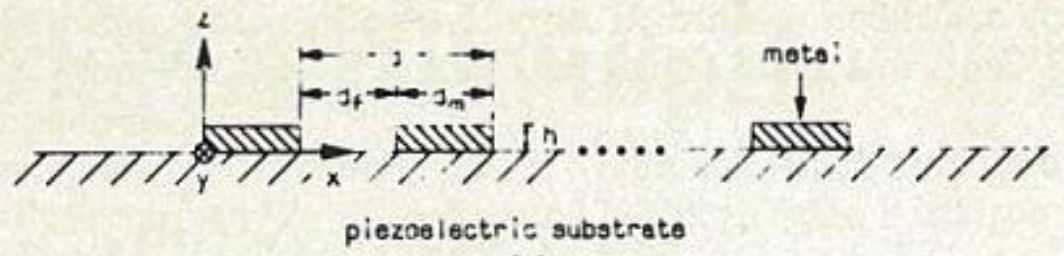

(a)

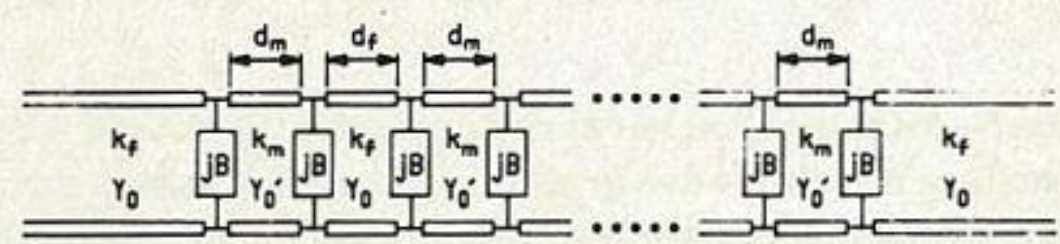

(b)

Fig. 2. Metallic grating. (a) Configuration. (b) Equivalent network.

where $\lambda_{f}$ is the wavelength for Rayleigh wave on free surface.

Noting that (8) should be satisfied and that the voltage standing wave distribution on equivalent network should be coincident with the electric potential distribution in substrate obtained by the FEM, from (4) and (5) only one pair of solutions appropriate to circuit parameters can be determined.

SAW reflection characteristics for groove or metallic gratings of finite periodic structure can be easily calculated by using the equivalent network in Fig. 1(b) or 2(b), respectively [20]. For the uniform array of $N$ grooves or $N$ metal strips the reflection coefficient $R_{N}$ is given by

$$
R_{N}=\frac{A_{N}-D_{N}+B_{N} Y_{0}-C_{N} / Y_{0}}{A_{N}+D_{N}+B_{N} Y_{0}+C_{N} / Y_{0}}
$$

where $A_{N}, B_{N}, C_{N}$, and $D_{N}$ are the elements of the transfer matrix for the uniform array.

\section{Computed Results}

First, we consider a groove array. Fig. 3 shows the magnitude of reflection coefficient per single groove (reflectivity per groove) and the normalized center-frequency shift (fractional frequency shift), where $\sigma$ is a Poisson's ratio for isotropic substrates and the fractional frequency shift (FFS) is given by

$$
\mathrm{FFS}=\left[\left(f_{u}+f_{l}\right) / 2-f_{0}\right] / f_{0} .
$$

Here $f_{0}=v_{f} / \lambda_{f}$ and $\lambda_{f}=2 d$. Our results for grooves on $Y-Z \mathrm{LiNbO}_{3}$ substrate agree well with the experimental results [21], [22]. For the $Y-Z \mathrm{LiNbO}_{3}$ substrate, two equivalent Poisson's ratios $\sigma=0.309$ [1] and $\sigma=0.335$ [2] have been proposed. Note that for the reflection per groove and the fractional frequency shift, our results obtained by using $\sigma=0.335$ and $\sigma=0.309$ are closer to those for the $Y-Z \mathrm{LiNbO}_{3}$ substrate, respectively.

Next, we consider aluminum (Al) strips on $X-112^{\circ} Y$ $\mathrm{LiTaO}_{3}, 34^{\circ} Y-X$ quartz, $Y-Z \mathrm{LiNbO}_{3}$, and $128^{\circ} Y-X \mathrm{Li}-$ $\mathrm{NbO}_{3}$ substrates. Both short and open circuited metallic gratings are treated. Figs. 4 and 5 show the values of $Y_{0}^{\prime} / Y_{0}-1$ and $B / Y_{0}$, respectively. Figs. 6 and 7 show the magnitude of reflection coefficient per two strips (reflectively per wavelength [15]) for short and open cir- 


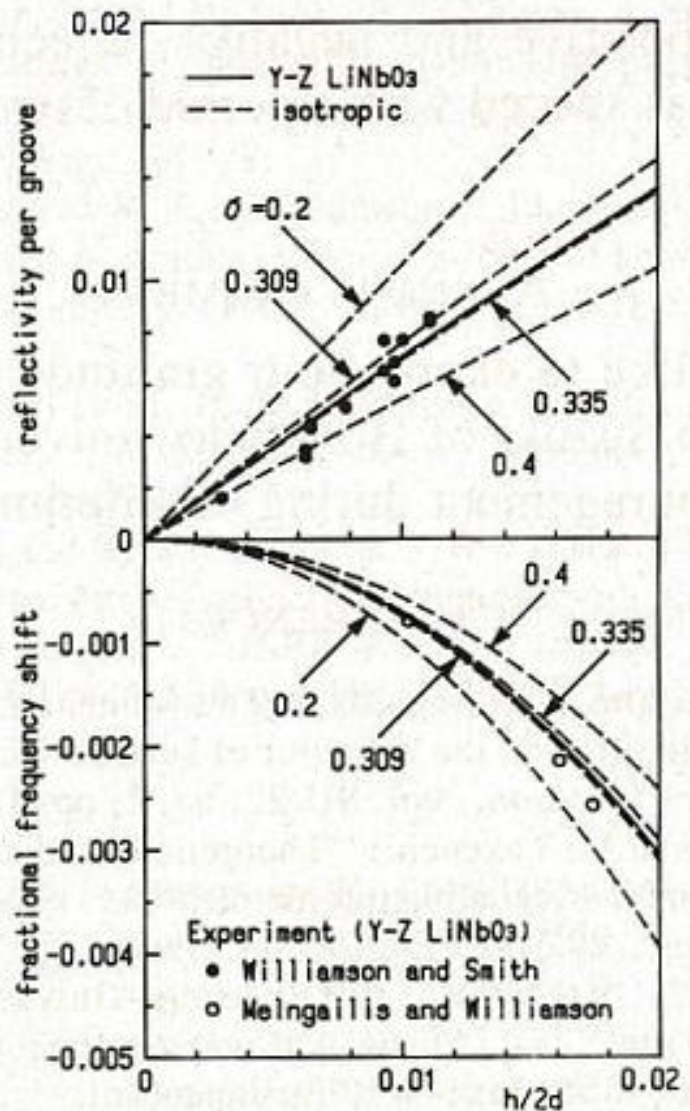

Fig. 3. Reflectivity per groove and fractional frequency shift for groove gratings.

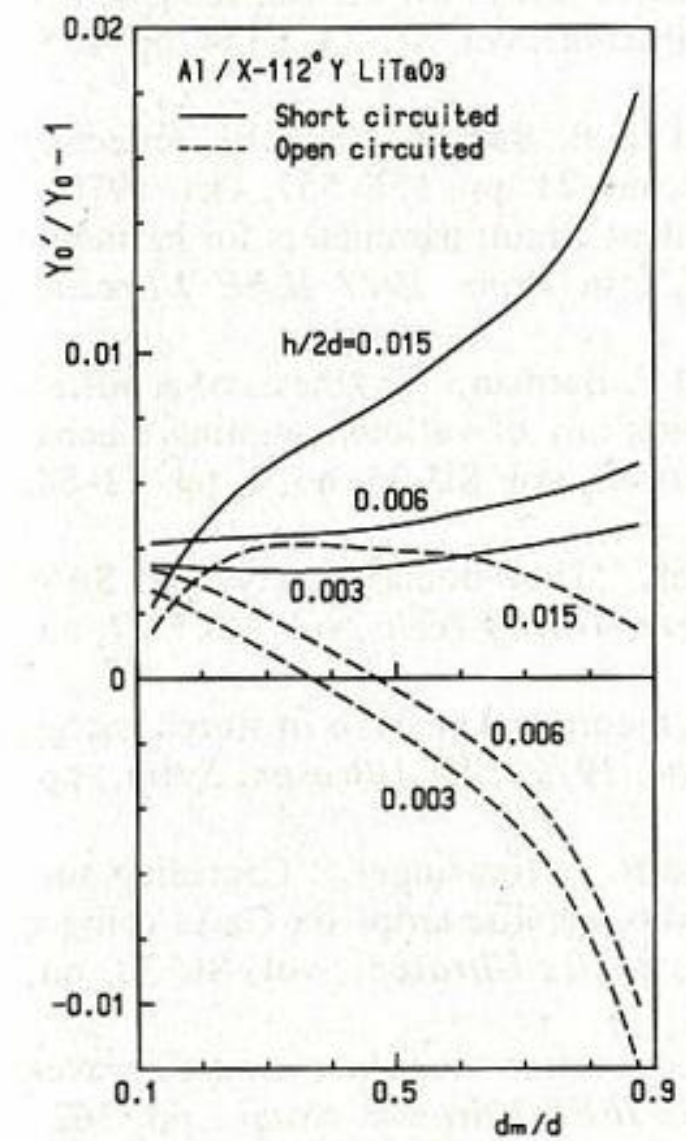

(a)

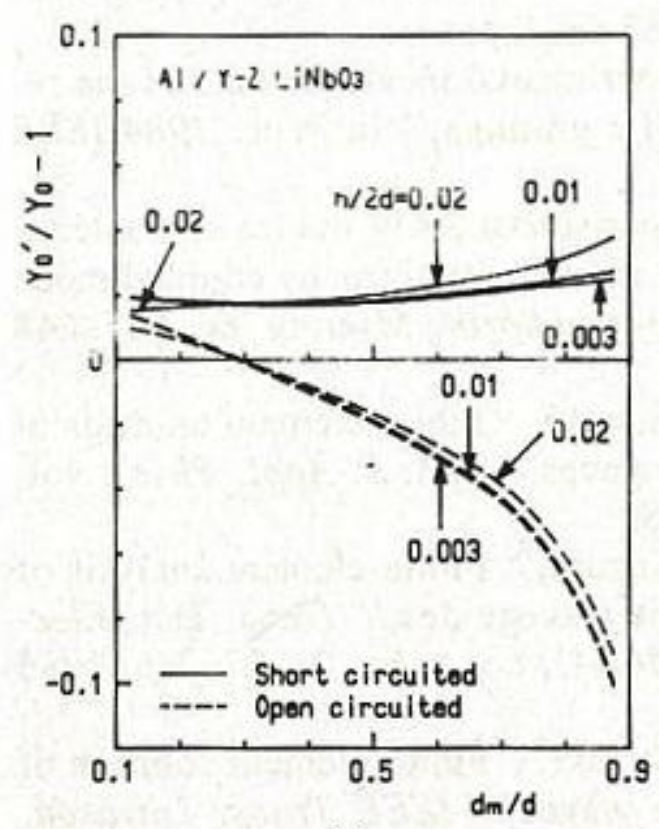

(c)

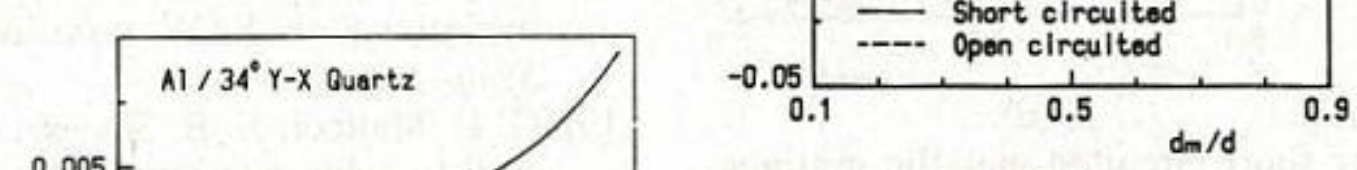

(c)

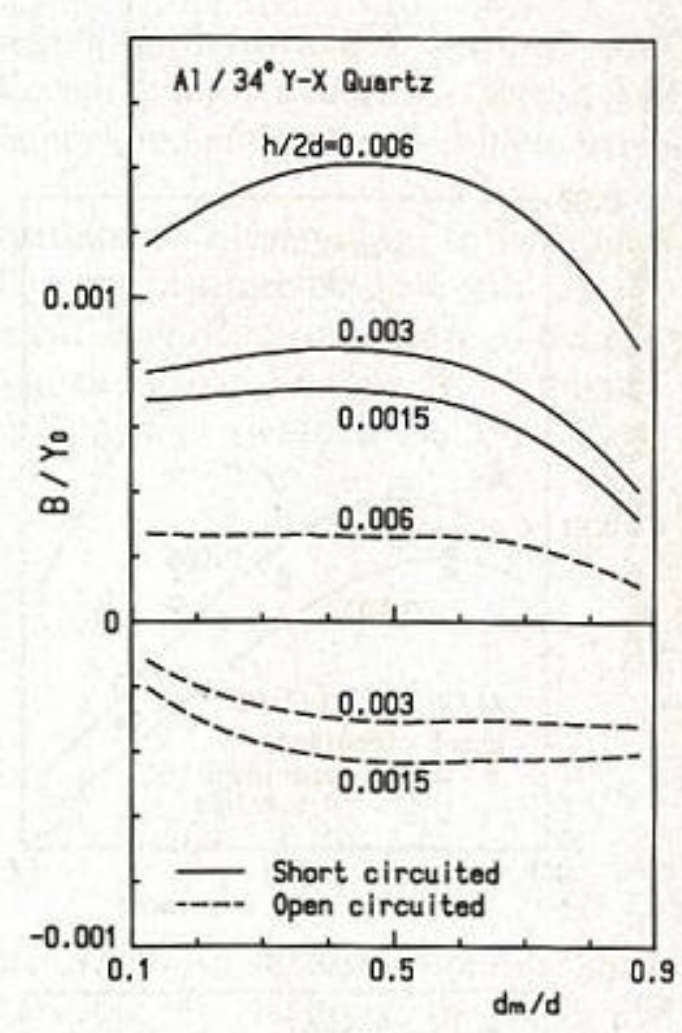

(b)

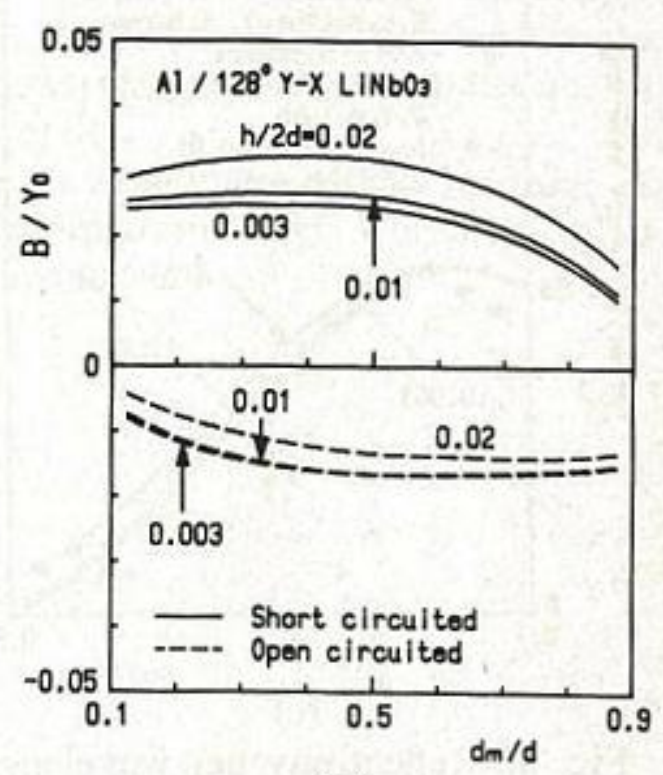

(d)
Fig. 5. Values of normalized susceptance. (a) $\mathrm{Al} / X-112^{\circ} \mathrm{Y} \mathrm{LiTaO}_{3}$. (b) $\mathrm{Al} / 34^{\circ} Y-X$ quartz. (c) $\mathrm{Al} / \mathrm{Y}-\mathrm{Z} \mathrm{LiNbO}_{3}$. (d) $\mathrm{Al} / 128^{\circ} Y-X \mathrm{LiNbO}_{3}$.

cuited metallic gratings, respectively. The reflectivity per single strip is one-half of the reflectivity per wavelength. Our results for $X-112^{\circ} Y \mathrm{LiTaO}_{3}$ and $34^{\circ} Y$-X quartz substrates agree well with the experimental results reported by Wright [15]. Our results for $Y-Z \mathrm{LiNbO}_{3}$ and $128^{\circ} Y-X$ $\mathrm{LiNbO}_{3}$ substrates, on the other hand, are different from these experimental results [15], and agree approximately with another experimental results [7] and the earlier theoretical results [23], [24].

The data in Figs. 3-7 may be useful for designing groove or metallic gratings.

\section{CONCLUSION}

An equivalent network approach was described for the analysis of SAW gratings. Circuit parameters can be theoretically determined by applying the FEM to an infinite array. In this approach, all of the effects of piezoelectric perturbation, mechanical perturbation, and energy storage are taken into account. Computed results for grooves or aluminum strips on a piezoelectric substrate agree well with the earlier theoretical and experimental results.

The frequency response of a uniform array can be easily calculated by using the equivalent network in Figs. 1(b) or 2(b) [20]. This approach may be applicable to new types of reflectors [24] consisting of reflecting elements 


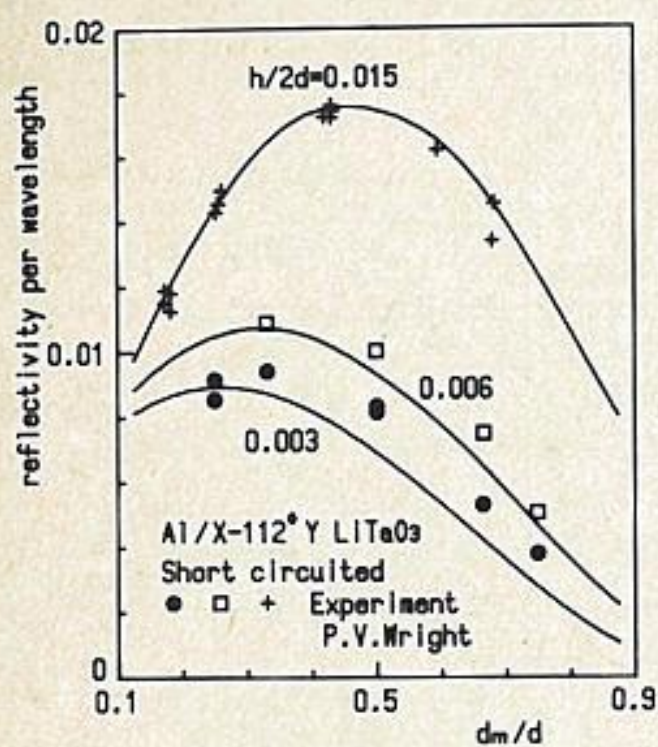

(a)

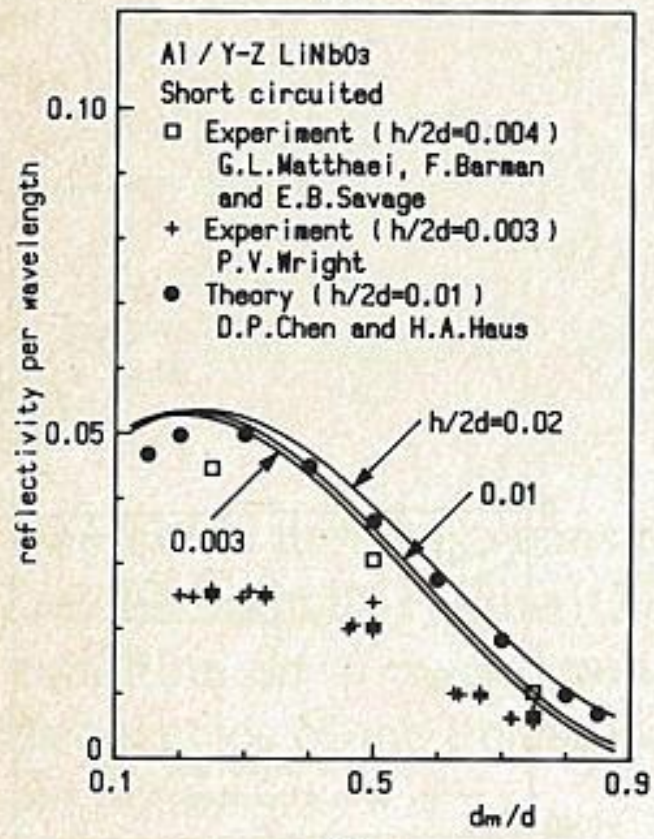

(c)

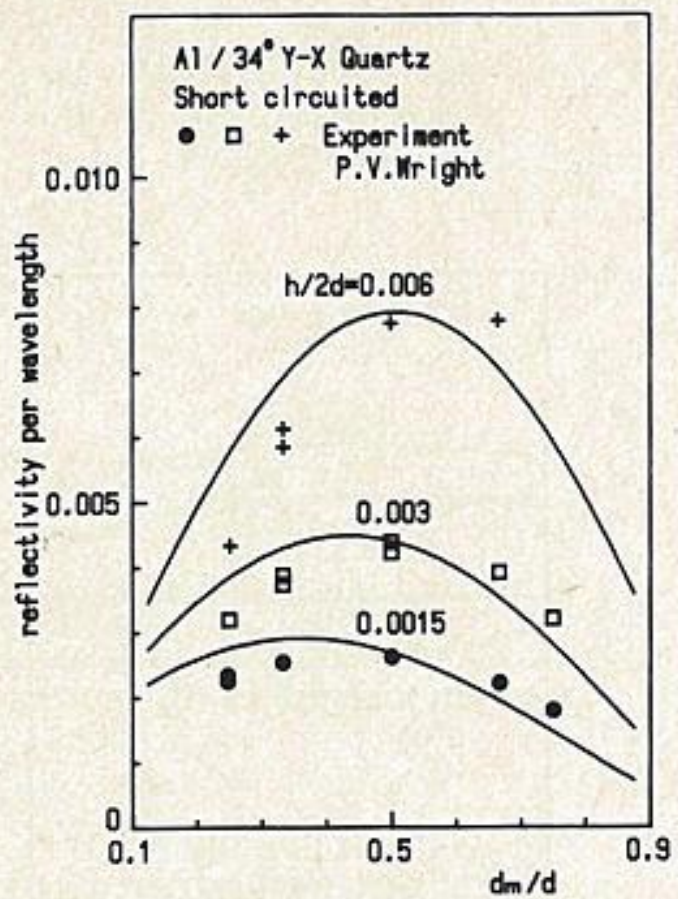

(b)

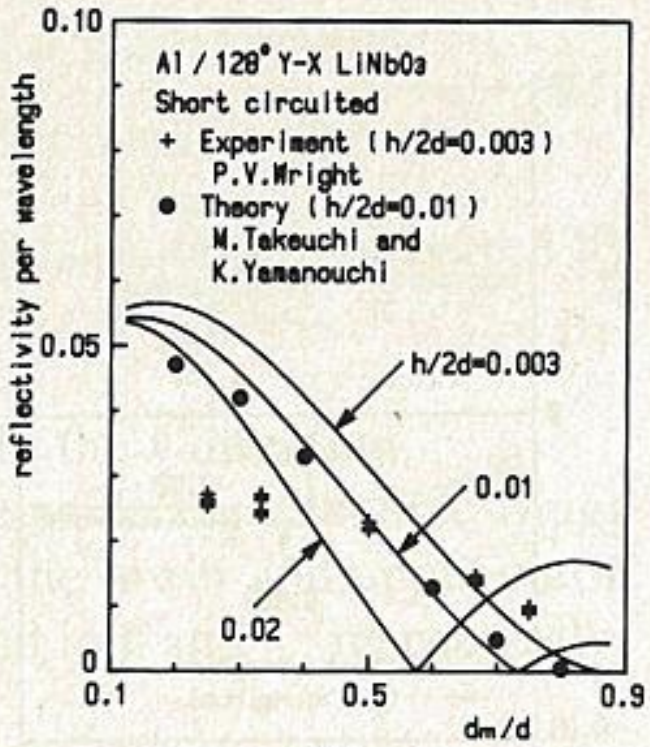

(d)
Fig. 6. Reflectivity per wavelength for short circuited metallic gratings. (a) $\mathrm{Al} / X-112^{\circ} Y \mathrm{LiTaO}_{3}$. (b) $\mathrm{Al} / 34^{\circ} Y-X$ quartz. (c) $\mathrm{Al} / Y-Z \mathrm{LiNbO}_{3}$. (d) $\mathrm{Al} / 128^{\circ} \mathrm{Y}-\mathrm{X} \mathrm{LiNbO}_{3}$.

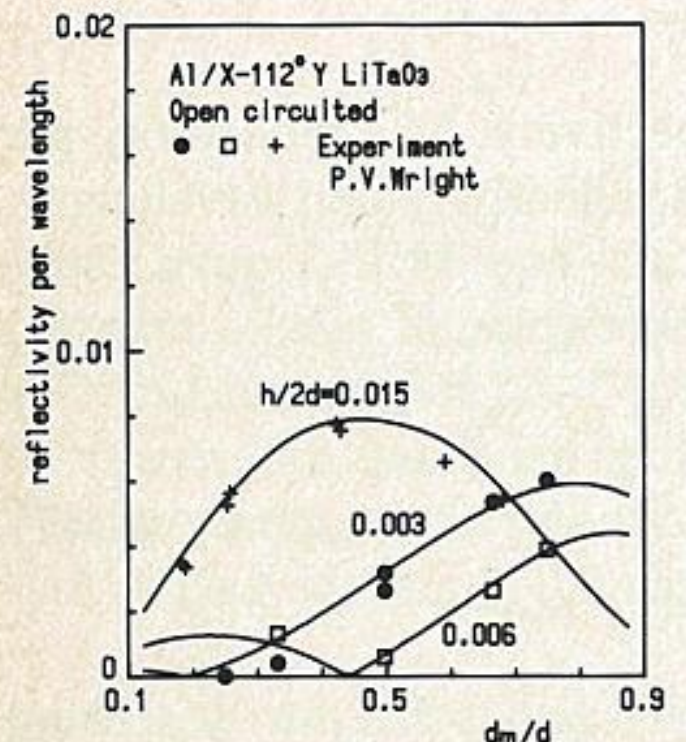

(a)

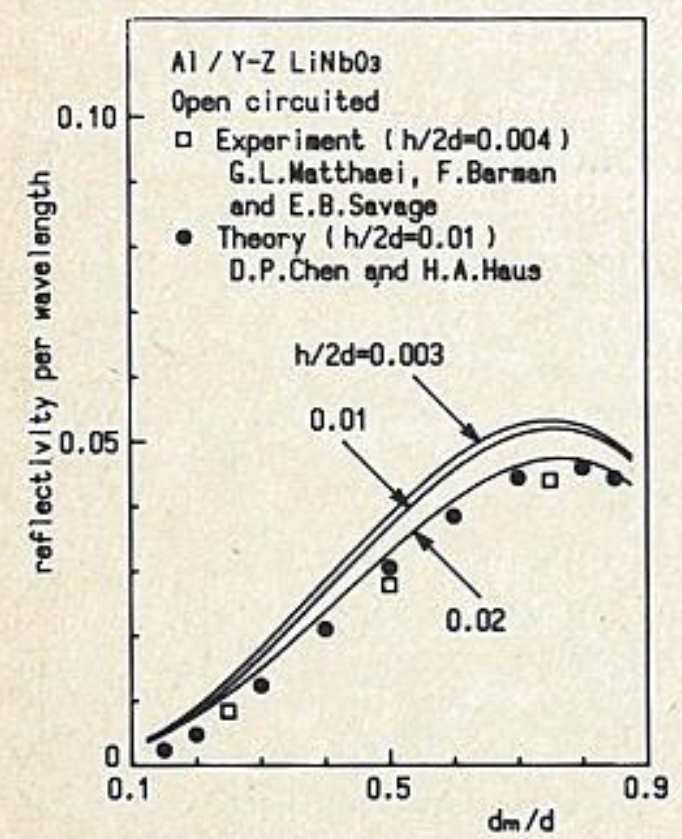

(c)

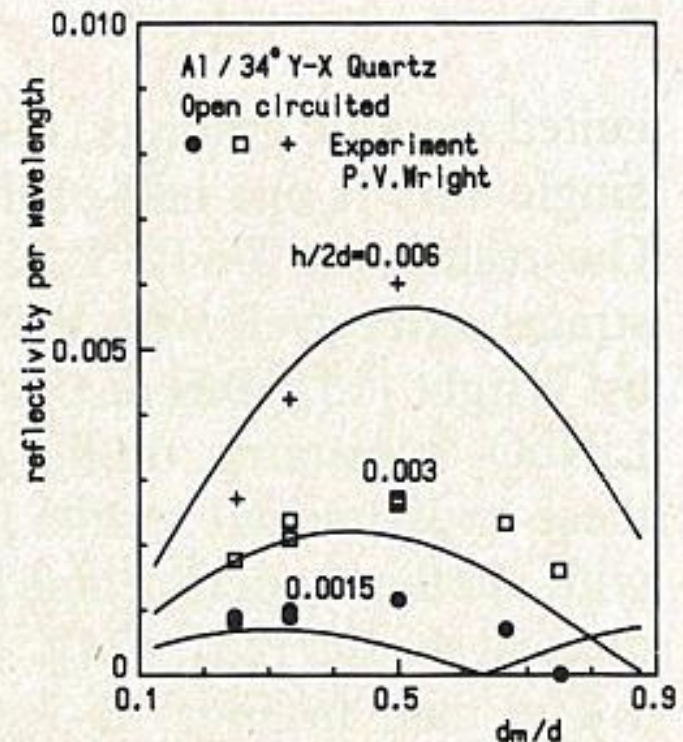

(b)

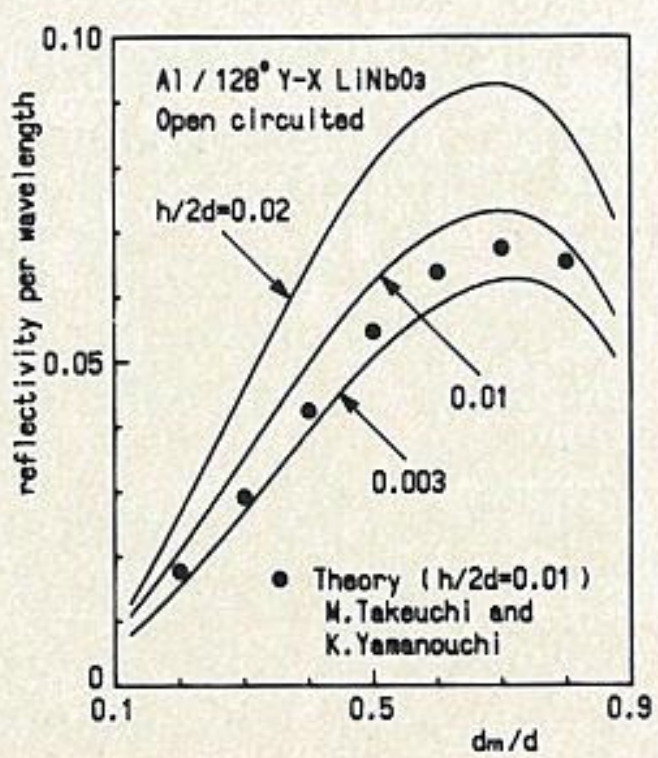

(d) with both a positive and negative reflectivity, in which each element is spaced with a period of one-quarter wavelength.

\section{ACKNOWLEDGMENT}

We would like to express our gratitude to the late Professor Michio Suzuki of Hokkaido University for his advice and encouragement during his lifetime.

\section{REFERENCES}

[1] R. C. M. Li and J. Melngailis, "The influence of stored energy at step discontinuities on the behavior of surface-wave gratings," IEEE Trans. Sonics Ultrason., vol. SU-22, no. 3, pp. 189-198, May 1975.

[2] H. Shimizu and M. Takeuchi, "Theoretical studies of the energy storage effects and the second harmonic responses of SAW reflection gratings," in Proc. 1979 IEEE Ultrason. Symp., pp. 667-672.

[3] Z. Kawasaki, "Analysis of the Bleustein-Gulyaev waveguides with gratings," Trans. Inst. Electron. Commun. Eng. Japan, vol. J62-B, no. 6, pp. 550-556, June 1979 (in Japanese).

[4] E. K. Sittig and G. A. Coquin, "Filters and dispersive delay lines using repetitively mismatched ultrasonic transmission lines," IEEE Trans. Sonics Ultrason., vol. SU-15, no. 2, pp. 111-119, Apr. 1968.

[5] G. L. Matthaei, B. P. O'Shaughnessy, and F. Barman, "Relations for analysis and design of surface-wave resonators," IEEE Trans. Sonics Ultrason., vol. SU-23, no. 2, pp. 99-107, Mar. 1976.

[6] P. S. Cross, "Properties of reflective arrays for surface acoustic resonators,'”IEEE Trans. Sonics Ultrason., vol. SU-23, no. 4, pp. 255 262, July 1976.

[7] G. L. Matthaei, F. Barman, and E. B. Savage, "S.A.W. reflecting arrays,"'Electron. Lett., vol. 12, no. 21, pp. 556-557, Oct. 1976.

[8] T. Aoki and S. Hattori, "Equivalent circuit parameters for harmonic operations on SAW transducer,"' in Proc. 1977 IEEE Ultrason. Symp., pp. 653-658.

[9] G. L. Mattaei, E. B. Savage, and F. Barman, "Synthesis of acousticsurface-wave-resonator filters using any of various coupling mechanism,"'IEEE Trans. Sonics Ultrason., vol. SU-25, no. 2, pp. 72-84, Mar. 1987.

[10] R. D. Fildes and B. J. Hunsinger, "Time domain analysis of SAW reflectors," IEEE Trans. Microwave Theory Tech., vol. MTT-27, no 2, pp. 194-198, Feb. 1979.

[11] S. Datta and B. J. Hunsinger, "A theoretical analysis of stored energy in surface wave gratings," in Proc. 1979 IEEE Ultrason. Symp., pp. 673-677.

[12] E. G. Bogus, M. J. Hoskins, and B. J. Hunsinger, "Canceling surface acoustic wave reflections from metallic strips on GaAs using a bimetal geometry,"' IEEE Trans. Sonics Ultrason., vol. SU-30, no. 5, pp. 317-320, Sept. 1983.

[13] S. Datta, "Reflection and mode conversion of surface acoustic waves in layered media," in Proc. 1983 IEEE Ultrason. Symp., pp. 362 368.

[14] Y. Ebata, S. Morishita, and K. Sato, "Surface acoustic wave resonator on $\mathrm{LiTaO}_{3}$ substrate and its application to oscillator of video tape recorder,"' Trans. Inst. Electron. Commun. Eng. Japan, vol. J66-C, no. 1, pp. 23-30, Jan. 1983 (in Japanese).

[15] P. V. Wright, "Modeling and experimental measurements of the reflection properties of SAW metallic gratings," in Proc. 1984 IEEE Ultrason. Symp., pp. 54-63.

[16] T. Kojima and T. Suzuki, "Comparison of SAW device characteristics analyzed by equivalent circuit model with those by coupled mode theory,"' Rep. 1986 Acoust. Soc. Japan Spring Meeting, pp. 647-648 (in Japanese).

[17] M. Koshiba, S. Mitobe, and M. Suzuki, "Finite-element anlaysis of periodic waveguides for acoustic waves," Jpn. J. Appl. Phys., vol 23, suppl. 23-1, pp. 139-141, 1984.

[18] S. Mitobe, M. Koshiba, and M. Suzuki, "Finite-element analysis of periodically perturbed piezoelectric waveguides," Trans. Inst. Electron. Commun. Eng. Japan, vol. J68-C, no. 1, pp. 21-27, Jan. 1985 (in Japanese).

[19] M. Koshiba, S. Mitobe, and M. Suzuki, "Finite-element solution of periodic waveguides for acoustic waves," IEEE Trans. Ultrason. Ferroelec. Freq. Contr., vol. UFFC-34, no. 4, pp. 472-477, July 1987.

[20] S. Mitobe, M. Koshiba, and M. Suzuki, "Theoretical determination of equivalent circuit parameters for reflective SAW metallic gratings," Trans. Inst. Electron. Commun. Eng. Japan, vol. J69-C, no. 7, pp. 884-892, July 1986 (in Japanese)
Fig. 7. Reflectivity per wavelength for open circuited metallic gratings. (a) $\mathrm{Al} / X-112^{\circ} Y \mathrm{LiTaO}_{3}$. (b) $\mathrm{Al} / 34^{\circ} Y-X$ quartz. (c) $\mathrm{Al} / Y-Z \mathrm{LiNbO}_{3}$. (d) $\mathrm{Al} / 128^{\circ} Y-X \mathrm{LiNbO}_{3}$ 
[21] R. C. Williamson and H. I. Smith, "The use of surface-elastic wave reflection gratings in large time-bandwidth pulse-compression filters,' IEEE Trans. Microwave Theory Tech., vol. MTT-21, no. 4, pp. 195-205, Apr. 1973.

[22] J. Melngailis and R. C. Williamson, "Interaction of surface waves and bulk waves in gratings: Phase shifts and sharp surface-wave/reflected bulk wave resonators,"' in Proc. 1978 IEEE Ultrason. Symp., pp. 632-629.

[23] D. P. Chen and H. A. Haus, "Analysis of metal-strip SAW gratings and transducers," IEEE Trans. Sonics Ultrason., vol. SU-32, no. 3, pp. 395-408, May 1985.

[24] M. Takeuchi and K. Yamanouchi, "New types of SAW reflectors and resonators consisting of reflecting elements with positive and negative reflection coefficients," IEEE Trans. Ultrason. Ferroelec., Freq. Contr., vol. UFFC-33, no. 4, pp. 369-374, July 1986.

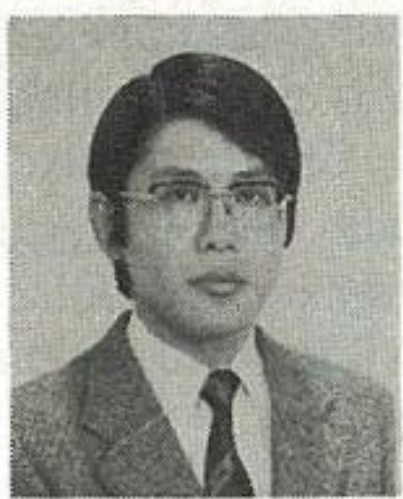

Masanori Koshiba (SM'84) was born in Sapporo, Japan, on November 23, 1948. He received the B.S., M.S., and Ph.D. degrees in electronic engineering in 1971, 1973, and 1976, respectively, from Hokkaido University, Sapporo, Japan.

In 1976, he joined the Department of Electronic Engineering, Kitami Institute of Technology, Kitami, Japan. From 1979 to 1987 , he was an Associate Professor of Electronic Engineering at Hokkaido University, and in 1987 he became a
Professor. He has been engaged in research on lightwave technology, surface acoustic waves, magnetostatic waves, microwave field theory, and applications of finite-element and boundary-element methods to field problems.

Dr. Koshiba is a member of the Institute of Electronics, Information, and Communication Engineers (IEICE), the Institute of Television Engineers of Japan, the Institute of Electrical Engineers of Japan, the Japan Society for Simulation Technology, and the Japan Society for Computational Methods in Engineering. In 1987, he was awarded the 1986 Paper Award by the IEICE.

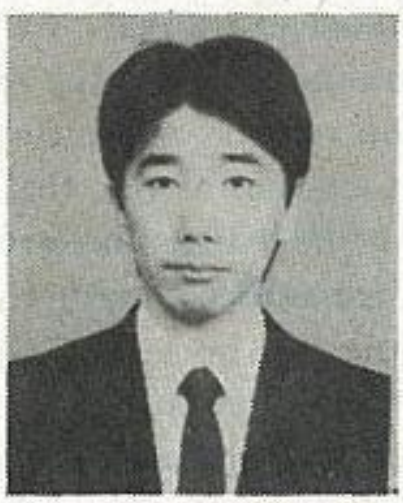

Seiichi Mitobe was born in Kamifurano, Japan, on January 7, 1960. He received the B.S. and M.S. degrees in electronic engineering in 1983 and 1985, respectively, from Hokkaido University, Sapporo, Japan. He is presently studying toward the Ph.D. degree in electronic engineering at Hokkaido University.

Mr. Mitobe is a member of the Institute of Electronics, Information, and Communication Engineers of Japan. 